\title{
LA ALTERIDAD INDÍGENA EN LOS LIBROS DE LECTURA DE ARGENTINA (CA. 1885-1940)
}

Por Teresa Laura Artieda. Madrid: Consejo Superior de Investigaciones Científicas, Colección de Acá y de Allá. Fuentes etnográficas, 2017. 167 páginas. ISBN 978-84-00-10258-6.

\section{LA PUREZA ESTÁ EN LA MEZCLA, QUE ANTES QUE PURO FUE MEZCLA ${ }^{1}$}

Los estudios sobre historia de la educación argentina hasta mediados de los años 1980 no reconocían las divergencias entre lo que se consideraba propio del campo de la historia de la educación y la educación formal que trazaba los límites de lo que debía ser investigado. ${ }^{2}$ El retorno al sistema político democrático, la reapertura de las universidades públicas, fundamentalmente en las áreas de Humanidades y Ciencias Sociales, y la preocupación por la colonización ideológica en el ámbito escolar fueron, entre otras razones, los motores que impulsaron una nueva etapa de la historia de la educación argentina como campo disciplinar.

Atravesados por una multitud de interrogantes y problemáticas de la sociedad contemporánea, al momento de la conformación de los grupos de investigación sobre el tema en las universidades locales predominó un planteo de tipo genealógico explicativo en términos de historia total, o al menos desarrollado con mayor profundidad para el caso de la provincia de Buenos Aires, que proyectaba para el resto del país un relato predominantemente descriptivo.

\footnotetext{
${ }^{1}$ Esta frase, recuperada por Teresa Artieda en las reflexiones finales del libro, pertenece a una canción del grupo español Jarabe de Palo.

2 Adrián Ascolani, «Actores, instituciones e ideas en la historiografía de la educación argentina», Educação 35, n. ${ }^{\circ} 1$ (2012): 42-53.
} 
Desde esta perspectiva, los estudios sobre la historia de la educación argentina tenían, entre otras, dos deudas con el pasado escolar. Por un lado, el vacío analítico respecto de la organización estatal provincial y el desarrollo de las primeras instituciones sociales que, a través de las juntas protectoras de escuelas o, por intermedio de las Sociedades de Beneficencia, moldearon el proceso de escolarización en las provincias. Por el otro, la ausencia en el análisis de los pueblos indígenas. Tema escasamente explorado para el período colonial, y prácticamente invisible durante el período de formación del Estado Nación, como si verdaderamente la escuela nos hubiera convencido de que la Patagonia estaba despoblada, y que, no obstante, el gran Chaco está poblado por indios salvajes.

Creo necesaria esta introducción para hablar del libro de Teresa Laura Artieda, en términos de la relevancia académica, sí, pero fundamentalmente por el aporte social que representa para nuestra memoria colectiva el estudio de esta temática, y con esta perspectiva. En La alteridad indígena en libros de lectura de Argentina (ca. 1885-1940), la autora analiza las imágenes acerca de los indígenas en libros de lectura escolares elaborados por maestras y maestros normales, editados en el auge del proyecto civilizatorio que entre finales del siglo XIX y los años 1940 configuró el imaginario colectivo hegemónico (de progreso) en Argentina. En este sentido, una de las preocupaciones fundamentales que organiza el estudio es develar la policromía de voces, las posiciones hegemónicas, las disrupciones y ambivalencias del relato. Al respecto, Ángel Díaz de Rada en el prólogo "Las grietas del silencio», enfatiza en el trabajo hecho con la complejidad de lo intertextual. Es decir, en el trabajo realizado para hacer explícitas las relaciones de poder que, durante años, la cultura escolar mantuvo ocultas.

Metodológicamente, el uso de los manuales escolares o libros de lectura se enmarca en procedimientos etnográficos utilizados por los historiadores para hacer una arqueología de la escuela. En este caso, son una herramienta para mostrar las concepciones de lo indígena entre los maestros. A partir de una selección de textos escolares que corresponden de 4to a 6to grado, dado el análisis que permite la extensión de las lecturas, Artieda estudia tres procesos simultáneos: la invasión del Estado nacional a los últimos territorios de los pueblos indígenas (17891911), la desarticulación de su modelo social y la transformación de su estatus político de pueblos soberanos a grupos étnicos sometidos, que 
coincidieron con los inicios y conformación del libro de lectura moderno en el país austral. Procesos que, para la autora, pertenecen al orden de lo contextual imprescindible para entender los contenidos de los libros y la versión de la historia (sobre esos mismos procesos) que en ellos se escribía.

Artieda señala que hubo una sincronía entre el ejercicio de la violencia del aparato represivo estatal y el de la violencia simbólica, plasmado en el poder unilateral de escribir las narrativas sobre esos conflictos y, por lo tanto, de forjar las imágenes de alteridad en esos libros. Contribuyeron a la configuración de esas representaciones la literatura de frontera, ${ }^{3}$ los informes de exploradores de los territorios indígenas incorporados al dominio estatal nacional y las obras plásticas más famosas que surgieron en esa época simbolizando el avance de la civilización sobre la barbarie. También la fotografía etnográfica que había capturado retratos indígenas, y los debates encabezados por las élites políticas y los intelectuales en torno del "problema indígena», sobre qué hacer con los sobrevivientes ante el peligro de la disgregación de la nación con la llegada de inmigrantes.

Pero el proceso histórico de relaciones entre la sociedad indígena y la criolla que transcurrió en paralelo a la edición de los libros escolares aquí analizados tuvo también otros momentos. Cumpliendo con el objetivo de dar lugar a la policromía de voces, Artieda recupera procesos de distinta índole, como la incorporación del indígena a las explotaciones económicas, los nacionalismos de principios del siglo xx que promovieron replanteos acerca de las raíces de la nación y el indigenismo, igualmente necesarios para comprender las lecturas sobre los indígenas en estos libros. En este punto, la autora analiza, entre otros textos, Isondú, de la maestra Elina González Acha, que incluye a los indígenas dentro de las raíces nacionales, como parte de las tradiciones argentinas; o el libro de lectura Río Nativo de la maestra Adelina Méndez Funes de Millán, que incorpora lo indígena bajo la forma de costumbres, cuyas diferencias explica en términos culturales y ambientales. Es el análisis de estas lecturas uno de los hallazgos más interesantes de la tesis, por-

\footnotetext{
${ }^{3}$ La literatura de frontera es un extenso corpus textual compuesto por diversos géneros narrativos, vinculado a la conquista del territorio y a la lucha contra el indio, que en Argentina se constituyó en un género en sí mismo.
} 
que rompe con miradas lisas de trabajos similares previos, que no dan cuenta de visiones diferentes, encontradas, y en algún sentido, cosifican la complejidad de las relaciones interétnicas.

Este libro presenta un amplio repertorio de fuentes sobre el período de la gestación y consolidación de los rasgos del libro de lectura moderno en Argentina, en el marco de la conformación y expansión del sistema de instrucción pública nacional, cuyo análisis está dividido en dos partes.

Primero, las narrativas escolares sobre el desembarco de Cristóbal Colón, la Conquista y la evangelización, y la historia de las relaciones entre las viejas estructuras de la sociedad colonial y la criolla, fundamentalmente a finales del siglo XIX, momento de alta tensión y conflictividad. Segundo, las imágenes de la alteridad indígena identificadas en los discursos textuales, entre los conflictos y ocupación de los territorios indígenas durante el proceso de formación estatal nacional (1880) y la fase siguiente de sometimiento e «integración» a la sociedad nacional. Para ello, Teresa Artieda consultó cerca de cien libros editados, reeditados e impresos entre 1880 y 1940 ca., en los que se identificaron aproximadamente 70 textos con 254 lecturas sobre los indígenas en Argentina y del continente americano en general.

En la primera parte del libro, la autora señala el poder instrumental de la escritura, en tanto que tiene la capacidad de conservar el pasado y al mismo tiempo comunicarlo indefinidamente, que expande el saber y por esta razón conserva una esencia colonizadora en sí misma. Y cita las palabras de una maestra indígena, de la comunidad qom del Chaco, que dice: «los libros [de lectura] fueron también como un arma secreta y silenciosa para volver a matarnos no solo ya con armas visibles sino con palabras; porque toda una generación leyó esos, lo que realmente es temible» (p. 23).

Con estas palabras, Teresa Artieda da paso a los capítulos I El desembarco de Cristóbal Colón, II Conquista y colonización, y III Conquista de los dominios indígenas en el actual territorio argentino, en los que analiza los discursos textuales.

A lo largo de los dos primeros capítulos, la clave para la autora es mostrar cómo en los libros de lectura se impugna la acción violenta de 
los conquistadores, mientras no se mencionan los hechos contemporáneos. En palabras de Artieda: «se reprueba la "destrucción", la "crueldad", la "monstruosidad", las "matanzas" de una conquista europea cómodamente distante» (p. 54). Esto es, teniendo en cuenta que el contexto de producción de los manuales escolares coincide con las expediciones militares en avance sobre los territorios indígenas, y las masacres llevadas a cabo para expulsarlos de sus tierras, luego de las cuales mujeres y niños eran entregados, en calidad de criados, a las familias acomodadas de los centros urbanos. Apoyados por los discursos cientificistas y darwinistas de la época, configuraron una representación de la otredad indígena en clave de inferioridad: bárbaros, sin lengua, religión, ley, armas, vestimenta o pudor. La mayoría de los libros analizados por la autora mantienen en silencio la obstinada resistencia de los pueblos indígenas, mientras se afanan en justificar la colonización a partir de la visión unilateral y hegemónica de las crónicas de viajes, y la acción evangelizadora de civilización.

En el capítulo III hay dos apartados. El primero, presenta una completa contextualización del momento de producción, con referencias en investigaciones clásicas y más recientes de antropología e historia relacionadas con la problemática de la frontera y las políticas estatales para los pueblos indígenas. En el apartado siguiente, Artieda reflexiona acerca de cómo ese pasado es narrado para los escolares. Pone en juego las interpretaciones que se cruzan acerca del malón, ${ }^{4}$ el papel que jugaron los fortines, ${ }^{5}$ como también, el lugar de otro actor invisible en el enfrentamiento entre la sociedad criolla y los pueblos indígenas: las fortineras, ${ }^{6}$ las mujeres. Identifica un proceso de cosificación del Otro en los textos, que se va naturalizando a través de una escritura distante, lejana, que dificulta el sentimiento de empatía con el indio/mujer. La reproducción de un discurso que legitima las acciones de las élites políticas para las cuales la vida indígena no tiene ningún valor, y peligro-

\footnotetext{
${ }^{4}$ Malón o maloca es un término araucano, que alude a las tácticas defensivas de los indígenas ante la necesidad de mantener su modo de existencia o responder a operaciones represivas de las tropas coloniales o criollas.

${ }^{5}$ Los fortines eran pequeños fuertes, ubicados en territorio no controlado por los criollos, que constituían las líneas defensivas desde donde los soldados vigilaban los campos del avance indígena.

${ }^{6}$ Fortinera, cuartelera o soldadera era el nombre que se le daba a las mujeres que acompañaban la vida de los soldados en los fortines durante la expansión de la frontera contra el indio.
} 
samente, se reproduce entre maestros y escolares, el desprecio por la vida humana. En este punto, la autora presenta un completo análisis de las representaciones de alteridad entre la pintura la «La vuelta del Malón», y el poema de Esteban Echeverría «La cautiva», por mencionar las fuentes más conocidas de entre el corpus documental presentado.

La segunda parte del libro profundiza en imágenes expresadas por medio de los discursos textuales, en sistemas de clasificación nosotros/ otros, esquemas interpretativos que configuraron imaginarios sobre los indígenas. Esta parte del libro está dividida en dos capítulos. En el capítulo 4 "Imágenes de antaño», se analizan las lecturas que tratan el tiempo del desembarco de Colón y el de la llegada de los españoles al actual territorio argentino. En el capítulo 5 «Imágenes de ogaño», examina las fuentes que reflejan las distintas etapas por las que pasaron las relaciones entre los pueblos indígenas y el poder político y la sociedad «blanca» en Argentina, entre el último cuarto del siglo XIX y las primeras décadas del siglo xx. Las expresiones antaño y ogaño, fueron tomadas de un libro de lectura en el que, para su autora, los indígenas representaban lo arcaico, explica Artieda. No obstante, señala la utilidad de esas denominaciones, por un lado, la idea de distancia, y por otro, la proximidad temporal que para la sociedad «blanca» de la época suponían los indígenas de los tiempos de la conquista y la colonia, y los colectivos indígenas contemporáneos. Unos, lejanos y exóticos, y los otros, como presencia concreta se tuviera o no contacto con ellos, respectivamente.

No obstante, Artieda plantea que se buscaba instalar a través de la figura del indígena el ícono de lo opuesto a lo mismo. A medida que la conquista se consolidó y comenzó a ser parte del pasado, ese ícono fue vaciado de subjetividad. "Somos un objeto de decoración, un adorno vistoso y olvidado en una esquina de la sociedad, somos un cuadro. Una foto, un tejido, una artesanía, nunca un ser humano», cita la autora parafraseando al EZLN. ${ }^{7}$

\footnotetext{
${ }^{7}$ Citado por Artieda, Teresa en la página 91. Ejército Zapatista de Liberación Nacional, en México. El EZLN es una organización político-militar formada mayoritariamente por grupos indígenas de los grupos tzeltal, tzotzil, chol, tojolabal y mam del Estado de Chiapas, cuya existencia se conoció públicamente el primero de enero de 1994 a raíz del levantamiento armado mediante el cual tomó la ciudad de San Cristóbal y poblaciones aledañas.
} 
En síntesis, en este libro la autora toma el compromiso de reflexionar acerca de la construcción de sentidos sobre lo indígena, generados por los agentes de la institución escolar o utilizados por esos agentes, durante la configuración y expansión del proyecto pedagógico argentino. Con ello señala una línea de estudios que, desde una mirada general de la nación, a partir del uso de unas fuentes concretas, los manuales escolares, sería interesante contrastar con el análisis de literaturas locales que, aunque no escolares, permitan identificar otras representaciones de lo indígena construidas desde su propia subjetividad.

Finalmente, un merecido comentario sobre la edición realizada por el Consejo Superior de Investigaciones Científicas de España que, con un cuidadoso tratamiento de las imágenes, permite a las lectoras entrar en contacto no solo con los textos y el vocabulario analizados en el libro, sino que a través de las fotografías nos acerca al discurso subliminal de esas representaciones de la alteridad indígena. Miradas frías y distantes, imágenes en blanco y negro, o caricaturas a color cuando la lejanía con los efectos de la conquista y colonización, en coincidencia con los efectos de la liquidación o expulsión de sus tierras, promovían la imagen del buen salvaje.

Antonela Centanni

UE-CISOR/CONICET, Universidad Nacional de Jujuy (Argentina) antonela.centanni@gmail.com 